\title{
ВЛИЯНИЕ ФАКТОРА ПРОИЗВОДИТЕЛЬНОСТИ НА КОНКУРЕНТОСПОСОБНОСТЬ ЭКОНОМИКИ В ЗАВИСИМОСТИ ОТ СРОКА СТРАТЕГИЧЕСКОГО ПЛАНИРОВАНИЯ
}

\section{INFLUENCE OF THE PRODUCTIVITY FACTOR ON THE COMPETITIVENESS DUE TO THE PERIOD OF STRATEGIC PLANNING \\ E. Ganshina}

Summary: The indicators of competitiveness, quality of life and productivity in the economy have no longer demonstrated such obvious interdependence since was previously thought in the classical theory of competitiveness by $\mathrm{M}$. Porter. The key factor in solving this problem seems to be a possible revision of the concept of productivity.

The data obtained in the course of the study demonstrates the existence of various options for achieving operational efficiency by an enterprise, depending on two different approaches - technological productivity and managerial productivity. Technological productivity is not connected and opposite contradicts the growth of the quality of life, and at the same time, in the short term, effectively ensures the competitiveness of an enterprise, industry, and national economy. At the same time, the quality of life at the national level (employee's satisfaction) is an important element of maintaining the same competitiveness in the long term.

The shorter the operational efficiency horizon, the less national companies invest in employee satisfaction, and vice versa. Accordingly, the type of productivity - technological or managerial - has a key impact on the quality of life.

It is concluded that considered in modern conditions of technological development, the provisions of Porter's theory of competitiveness can be revised developing a short-term development strategy, but remains valid with a long-term planning horizon.

The results of the research based on the analysis of empirical data from a number of the largest Russian companies in the manufacturing sector make it possible to predict the vector of economic development and have be used by enterprises planning strategic initiatives and identifying sources of growth.

Keywords: productivity, competitiveness, quality of life, personnel satisfaction, operational efficiency, long-term planning, sustainable development, development strategy, strategic goals, technological progress.

\section{Постановка проблемы}

перационная эффективность как область анализа производственной деятельности, и процессов с ней связанных, выделяет и препарирует выигрыши в производительности как с точки зрения практик
Ганьшина Елена Юрьевна

К.э.н., Старший преподаватель, Финансовый университет при Правительстве Российской Федерации

e.ganshina@inbox.ru

Аннотация: Показатели конкурентоспособности, качества жизни населения и производительности в экономике уже не демонстрируют столь очевидной взаимозависимости, как представлялось ранее в классической теории конкурентоспособности М. Портера. Ключевым фактором в решении данной проблемы представляется возможный пересмотр понятия производительности.

В работе изложены полученные в ходе исследования данные о существовании различных вариантов достижения предприятием операционной эффективности в зависимости от двух разных подходов -производительности технологической и производительности управленческой. Технологическая производительность не связана, а подчас противоречит, росту качества жизни и при этом в краткосрочной перспективе эффективно обеспечивает конкурентоспособность предприятия, отрасли, национальной экономики. Но качество жизни на национальном уровне (удовлетворенность сотрудников - на мезо-уровне) абсолютно необходимый элемент поддержания той же самой конкурентоспособности в долгосрочной перспективе.

Чем короче горизонт операционной эффективности, тем меньше национальные компании инвестируют в удовлетворенность сотрудников, и наоборот. Соответственно, тип производительности - технологический или управленческий - оказывает ключевое влияние на качество жизни.

Сделан вывод, что, при рассмотрении в современных условиях технологического развития, положения теории конкурентоспособности Портера могут быть пересмотрены при разработке краткосрочной стратегии развития, но остается справедливым при долгосрочном горизонте планирования.

Результаты исследования, основываясь на анализе эмпирических данных ряда крупнейших российских компаний производственного сектора, позволяют спрогнозировать вектор развития экономики, а также могут быть использованы предприятиями при планировании стратегических инициатив и выявлении источников роста.

Ключевые слова: производительность, конкурентоспособность, качество жизни, удовлетворенность персонала, операционная эффективность, долгосрочное планирование, устойчивое развитие, стратегия развития, стратегические цели, технологический прогресс. 
конкурентоспособность на глобальном уровне, определяют способность компаний данной страны успешно конкурировать на региональных и международных рынках $[1,2]$. Именно поэтому производительность остается центральной темой экономических дебатов как за рубежом, так и в России [3-5].

Производительность в классической теории, основанной на работах М. Портера, всегда шла рука об руку не только с конкурентоспособностью, но и с качеством жизни. Однако, тенденции последнего времени показывают отсутствие прямой корреляции этих показателей, особенно на краткосрочных отрезках времени, перспективе 5-7 лет [6, 7]. Проблема заключается в том, что рост производительности может обходиться без параллельного роста качества жизни населения. Более того, конкурентоспособность не всегда зависит от механистического роста производительности [8].

В период ускорения технологического прогресса, сжимания сроков внедрения инноваций, молниеносного закрытия целых отраслей экономики, вызванных появление новых прорывных инноваций или бизнесмоделей, сокращаются и горизонты планирования, и время прохождения компаниями своих естественных жизненных циклов [9]. Иногда стартапу достаточно трехпяти лет, чтобы претендовать на лидерские позиции в отрасли. Стоит ли при таком бурном росте обращать внимание на удовлетворенность сотрудников? Или можно обойтись внедрением технологических новинок и обеспечить таким образом конкурентоспособность компании без дополнительных затрат на взаимодействие с персоналом?

С одной стороны, забота о сотрудниках предполагает создание систем гибкого управления оплатой труда, разработку социальных льгот рабочей силы, внедрение программ обучения, адаптации, медицинского сопровождения $[10,11]$. Все это может быть дорогостоящей задачей в краткосрочной перспективе и приведет к росту издержек, что в свою очередь окажет давление на общий уровень конкурентоспособности компании. Поэтому баланс между пожеланиями работников и требованиями производственной эффективности соблюсти подчас очень сложно [12].

С другой стороны, компания, которая заботиться о своих сотрудниках, может быть более конкурентоспособной в долгосрочной перспективе, потому что она благодаря своему более расширенному пакету льгот и гарантий привлечет более качественных соискателей на работу, а значит будет обладать дополнительными преимуществами по сравнению со своими конкурентами, которые смогут выбирать из менее качественных кандидатов.
Учитывая, что конкурентоспособные компании формируют конкурентоспособные отрасли экономики той или иной страны, которые в свою очередь обеспечивают национальную конкурентоспособность, то данные тенденции можно вполне справедливо перенести как на национальные отрасли экономики, так и национальных производителей как основных субъектов данных экономических систем.

В последнее время появляется все больше исследований, которые, основываясь на статистических данных, показывают, что модель одновременного роста в рамках триады «национальная конкурентоспособность - качество жизни - производительность» не работает или работает некорректно [13-15]. Внимание привлекает отсутствие корреляции между ростом этих показателей при анализе экономического развития ряда крупнейших экономик планеты. Например, С.В. Шкиотов сравнивает показатели уровня национальной конкурентоспособности, качества жизни населения и производительности труда экономик стран БРИКС и делает вывод, что между исследуемыми показателями отсутствует прямая зависимость, тем самым ставя под сомнение одно из фундаментальных положений теории Портера [6].

Можно предположить, что краткосрочная стратегия предприятия допускает исключение издержек компании на достижение удовлетворенности персонала, который на данном горизонте планирования не имеет существенного влияния на конкурентоспособность, так как замещается ростом технологической производительности. Однако, эффект технологического роста исчерпаем. При долгосрочной стратегии выживания на региональном рынке вектор влияния производительности на конкурентоспособность смещается от технологических усовершенствований к управленческим, которые неизбежно должны включать в себя рост удовлетворенности персонала. Это хорошо просматривается на основании анализа опыта реинжиниринга национальных компаний для достижения большей операционной эффективности из наиболее конкурентоспособных отраслей экономики.

\section{Эмпирические Аанные}

Первый подход - Технологическая производительность. Организационная эффективность (производительность) может быть увеличена за счет приобретения новых технологий и оборудования (автоматизации) производственных процессов для более эффективного производства товаров и услуг путем сокращения себестоимости товаров. Этот подход увеличивает интенсивность капитализации компании и может приводить к сокращению рабочих мест путем краткосрочного сокращения штата. Сокращения, естественно, приводят к снижению удовлетворенности у сотрудников, даже оставшихся работать в компании, однако не отражается на сиюминут- 
ных показателях производительности. Компания воспринимает такой обмен (рост производительности при снижении удовлетворенности), как позитивный, потому что улучшенная операционная эффективность растёт с помощью большей интенсивности капитализации и меньших трудозатрат. Например, Новолипецкий металлургический комбинат внедрил на своем производстве модель построения прогноза по выходу из строя критичного производственного оборудования, что позволило в кратчайшие сроки снизить затраты на обслуживание оборудования, сократить простой данного оборудования, и за счет этого производительность доменной печи на $20 \%$ [16].

Показатели производительности труда росли вплоть до 2017 года, однако, в 2018 году данный показатель начал стагнировать, а в 2019 году и вовсе упал, несмотря на устойчивых спрос на продукцию НЛМК на мировых рынках до начала пандемии 2020 года.

Таблица 1.

Ключевые операционные показатели Группы НЛМК за период 2012-2019 гг.

\begin{tabular}{|l|c|c|c|c|c|c|c|c|}
\hline $\begin{array}{l}\text { Операционные } \\
\text { показатели }\end{array}$ & 2012 & 2013 & 2014 & 2015 & 2016 & 2017 & 2018 & 2019 \\
\hline $\begin{array}{l}\text { Численность, } \\
\text { тыс. чел. }\end{array}$ & 62,5 & 62,1 & 60,1 & 56,7 & 54,0 & 53,2 & 53,3 & 52,8 \\
\hline $\begin{array}{l}\text { Производительность } \\
\text { труда по Группе, } \\
\text { т/чел. }\end{array}$ & 406 & 420 & 437 & 463 & 482 & 502 & 503 & 448 \\
\hline
\end{tabular}

Источник: Финансовые результаты ПАО «СИБУР Холдинг» - [Электронный ресурс]. URL: http://investors.sibur. com/results-centre/financial-results.aspx?sc_lang=ru-RU (дата обращения: 31.07.2020)

В этот же период Группа НЛМК объявляет новый этап стратегии, рассчитанной до 2022 и предполагающей органический рост за счет внедрения программ повышения операционной эффективности без инвестиций.

Второй подход - Управленческая прочзводительHOCMb.

Автоматизацией бизнес-процессов и построением прогнозных моделей для повышения норм производительности (например, разработка модели, позволяющей найти и разместить аномалии в данных, выявить изменения паттернов сигнала и т.д.) изначально была занята и другая флагманская для своей отрасли компания - холдинг «СИБУР». Однако, со временем вектор развития сместился в сторону реинжиниринга не только производственных, но в основном и в первую очередь управленческих процессов. Это привело к закономерному росту затрат холдинга на персонал, оплату труда, системы обучения, IT, однако позволило руководству холдинга говорить о системности управления и переходу на устойчивое развитие, то есть развитие, ориентированное на поддержание конкурентоспособности предприятий Группы на долгосрочную перспективу, заявить лидерские притязания не только на национальном рынке, но и в нефтехимической промышленности на глобальном уровне.

В 2015 году в СИБУРе началась реализация проекта «Разработка и внедрение интегрированной системы менеджмента», которая включала в себя ряд программ по повышению качества управления персоналом одновременно с получением соответствующих сертификатов, подтверждающих соответствие требованиям международных стандартов. В рамках внедрения интегрированной системы менеджмента (ИСМ) было получено четыре сертификата. ISO 9001:2008 (система менеджмента качества), ISO 14001:2004 (система экологического менеджмента) и OHSAS 18001:2007 (охрана профессионального здоровья) получены для корпоративного центра и 26 площадок компании, а сертификат по ISO 50001 (система энергоменеджмента) - для корпоративного центра и девяти площадок.

Сертификация показала хорошие результаты и в 2016 году в СИБУРе в рамках процесса реинжиниринга были созданы рабочие группы из представителей разных функций из центрального офиса, предприятий и проектного офиса («СИБУР-ЦОБ»). Главной задачей данных рабочих групп являлась разработка мероприятий по улучшению на первоначальном этапе 10, в последствии 12 , процессов, которые признавались в компании самыми «болезненными».

Все это на первоначальном этапе, естественно, потребовало инвестиций. Если за период 2011-2017 гг., то есть за 7 лет, инвестиции СИБУРа на техобслуживание, НИОКР, ИТ и прочее (включая фонд оплаты труда) составили 1,9 млрд. долл. США (11,5\% от общей инвестиционной программы Холдинга), то на последующие 3 года, 2018-2020 гг., инвестиции закладывались уже в районе 1 млрд. долл. США, что составляло почти 19\% от общей суммы инвестиций, наравне с обслуживанием инфраструктуры по переработке сырья, затратам на транспорт и нефтехимию. Расходы на персонал стабилизировались лишь к 2020 году, их рост по итогам 1-го квартала 2020 г. составил лишь +2\% по сравнению с аналогичным показателем 2019 г.

Если рассматривать вышеуказанные данные комплексно, то для нас не столько важен рост издержек, сколько их влияние на изменение производительности труда. Численность персонала СИБУРа за четыре года программы реинжиниринга с 2015 по 2018 гг. оставался почти неизменным, а вот выручка в расчете на одного сотрудника возросла за 5 лет почти на $60 \%$ и осталась 
неизменной даже при существенном сокращении персонала в 2019 году.

Таблица 2.

Ключевые операционные показатели Холдинга «СИБУР» за период 2014-2019 гг.

\begin{tabular}{|l|l|l|l|l|l|l|}
\hline Операционные показатели & 2014 & 2015 & 2016 & 2017 & 2018 & 2019 \\
\hline $\begin{array}{l}\text { Среднесписочная численность, } \\
\text { тыс. чел. }\end{array}$ & 25,9 & 27,1 & 27,7 & 27,3 & 27,3 & 22,9 \\
\hline $\begin{array}{l}\text { Производительность труда по } \\
\text { Холдингу, млн руб./чел. }\end{array}$ & 12,3 & 14,0 & 14,9 & 16,6 & 20,9 & 20,8 \\
\hline
\end{tabular}

Источник: составлено автором по материалам презентаций СИБУР для инвесторов (http://investors.sibur. com)

Все это соответствует долгосрочному тренду достижения стратегических целей по созданию коммерческой ценности на длительный период.

Рост удовлетворенности сотрудников сопровождается ростом издержек бизнеса на разработки дорогостоящих программ для персонала, что

А) снижает текущую конкурентоспособность компании;

Б) приводит к краткосрочному росту производительности.

To ectb,

Производительность (П $\mathrm{t} 1)+$ издержки = Удовлетворенность - Конкурентоспособность

Если компания не несет издержек на удовлетворенность персонала, то иллюстрация процесса несколько меняется

Конкурентоспособность - издержки - Удовлетворенность = Производительность (П t1)

Таким образом, в краткосрочной перспективе

Производительность + Удовлетворенность $\neq$ Конкурентоспособность

Если анализировать деятельность компаний, в нашем случае мы приводим практику российских производителей, то выстраивается тенденция постепенной трансформации от борьбы за производительность путем снижения издержек и внедрения инноваций к переходу к поступательному росту производительности как залогу конкурентного преимущества, которое обеспечивается креативными, хорошо обученными сотрудниками. Данную конфигурацию гораздо сложнее воспроизвести, чем простое вложение средств в капитальные улучшения, но она закладывает основы для роста конкурентоспособности в долгосрочной перспективе. В этом случае модель Портера выглядит справедливо и поддержание конкурентоспособности компании на всем периоде жизненного цикла организации может схематично выглядеть как:

$$
(П \mathrm{t} 1-\mathrm{y} \mathrm{t} 1)-\text { Издержки })+(П \mathrm{t} 1+\mathrm{y} \mathrm{t} 2)+\text { Из- }
$$$$
\text { держки) }=\text { Конкурентоспособность }(\mathrm{n})
$$

, где $\mathrm{t} 1$ - показатели краткосрочного периода, t2 - показатели долгосрочного периода.

\section{Зак^ючение}

При задаче достичь быстрых результатов, обеспечить прибыль бизнеса здесь и сейчас, издержки на развитие персонала избыточны, так как негативно отражаются на конкурентоспособности компании. Если же компания ориентирована на долгосрочное присутствие на рынке, то развитие за счет технологических инноваций только в производство является недолговидной стратегией, так как имеет определенный срок эффективности, особенно учитывая сокращение жизненного цикла продукта, переход на новые материалы, изменение поведенческих характеристик потребителя. Такие тренды могут отследить и дать им адекватный ответ только люди, и чем более квалифицированными они будут, чем лучше для долгосрочной конкурентоспособности компании.

Ускорение технологического процесса, применение методов искусственного интеллекта вносят свои коррективы в закономерности ранее незыблемых теорий. Теория конкурентоспособности Портера при рассмотрении тенденций на кратковременном временном промежутке может быть подвергнута критическому переосмыслению. Конкурентоспособность национальных компаний, а значит и экономики страны в целом, может повышаться за счет технологических нововведений, которые никак не связаны с повышением удовлетворенности работников, а значит, и с ростом качества жизни населения страны. Показатели ряда развивающихся стран, в том числе России, наглядно показывают, что качество жизни не является необходимым условием роста производительности и конкурентоспособности региона в краткосрочной перспективе.

Однако, качество жизни напрямую влияет на стабильность развития, его устойчивость. Технологическая производительность позволяет нарастить выработку, но на короткий период. Потенциал искусственного механистического роста конечен. Устойчивое экономическое развитие представляется более перспективным с точки зрения конкурентных преимуществ, так как достигается за счет связи между удовлетворением потребностей сотрудников, гибкостью рабочей силы и производительностью не механистического, а управленческого типа. В этой связи представляется вполне логичным разделить понятия технологическая производительность (П t1) и управленческая производительность (П t2). Таким об- 
разом, при рассмотрении долгосрочных перспектив, с достижением производительности по типу П t2, фундаментальные положения теории Портера не теряют своей актуальности.

От того, какую стратегию конкурентоспособности выберут ведущие национальные компании, зависит конкурентоспособность экономики страны в целом. При этом, чем меньше компании уверены в возмож- ности действенно влиять на свое рыночное будущее и обстоятельства в нем, тем на более короткий срок происходит планирование. Если компании не закладывают долгосрочный паттерн развития, то они не вкладывают средства в удовлетворенность сотрудников, а значит на национальном уровне не растет качество жизни. Это может стать ключевой проблемой в задаче сохранения конкурентоспособности страны и региона ее экономического влияния в долгосрочной перспективе.

\section{ЛИТЕРАТУРА}

1. К Конкурентоспособность России в глобальной экономике / под рук. А. Дынкина, Ю.М. Куренкова. - М.: Международные отношения, 2003. - 376 с.

2. Кругман П.Р., Обстфельд М. Международная экономика: теория и политика / пер. с англ. 5-го межд. изд. - СПб.: Питер, 2004. - 832 с.

3. Устюжанина Е.В., Губарев Р.В., Искандарян Р.А. и др. Социальная политика и ее влияние на производительность труда // Вестник Российского экономического университета имени Г.В. Плеханова. - 2020. - №2. - С. 51-65. doi.10.21686/2413-2829-2020-1-51-65

4. Гоффе Н., Монусова Г. Социальные источники производительности труда// Социальный контекст экономи ᄀческого развития в XXI веке. - М.: ИМЭМО PAH, 2016. - C. 54-77.

5. Сухарев О.С. Виды эффективности в экономике: современная трактовка // Инвестиции в России. - 2009. - №1. - С. 17-23; 2009 - №4. - С. 18-24; 2009 №5. - С. 36-44.

6. Шкиотов С.В. Верификация модели национально конкурентоспособности М. Портера на примере стран БРИКС // Экономический анализ: теория и практика. - 2014. - №2. - C. 45-53.

7. A Tale of Two Mexicos: Growth and Prosperity in Two-Speed Economy. - New York: McKinsey Global Institute, March 2014. $\neg-104 \mathrm{p}$.

8. Schultz T.W. Investment in Human Capital // American Economic Review. - 1961. - № 1 - pp. 1-17.

9. Адизес И. Управление жизненным циклом корпораций. - М.: Манн, Иванов и Фербер, 2014. - 700 с.

10. Мотивация и стимулирование трудовой деятельности/ Кибанов А.Я., Баткаева И.А., Митрофанов Е.А. и др. - М.: ИНФРА-М, $2012 .-524$ с.

11. Сухарев 0.С. Теория эффективности экономики. - М.: Финансы и статистика, 2009. - 369 с.

12. Behind the American Export Surge: The U.S. as One of the Developed World's Lowest-Cost Manufactures. - Chicago: BCG Focus, 2013. - 18 p.

13. Smit A.J. The competitive advantage of nations: is Porter's Diamond Framework a new theory that explains the international competitiveness of countries? // Southern African Business Review, 2010, Volume 14 (1), pp. 105-130.

14. Waverman L.A critical analysis of Porter's framework on the competitive advantage of nations // Rugman, A.M., Van Den Broec, J. and Verbeke, A. (Ed.) Beyond The Diamond (Research in Global Strategic Management, Vol. 5. $\neg$ - Bingley: Emerald Group Publishing Limited, 1995. $\neg-$ pp. 67-95.

15. Catwright W. Canada at the Crossroads Dialogue. - W. Catwright, Business Quarterly, Vol. 57, 1992. - pp. 10-12.

16. Ганьшина Е.Ю. Цифровизация как источник возмещения капитала - решения, меняющие бизнес// Инновации и инвестиции. - 2019. ᄀ- №9. - С. 50-55. 